\title{
The Issues of Post-Lichtenstein Chronic Groin Pain
}

\author{
B. Ramana ${ }^{1} \cdot$ Brijesh Dube ${ }^{2}$
}

Accepted: 10 January 2021 / Published online: 4 February 2021

(C) Société Internationale de Chirurgie 2021, corrected publication 2021

Post-inguinal herniorrhaphy pain is a topic on which there is no clear consensus among surgeons about its definition, prevalence and causes. Among patients, it may be perceived to be a mesh-related complication, with serious medicolegal implications in different countries. For example, in Australia, regulators have classified hernia mesh as Class III (high risk) [1].

The varied incidence of chronic postoperative inguinal pain (CPIP) is reflected in the published literature, as reported by the authors, from 0 to 53 percent [2].

There are multiple etiological factors leading to this often-distressing condition involving the patient, the mesh and the surgeon, often in some combination.

We do not have clarity on the causation, prevention and management of CPIP from published literature on the subject, one reason being that studies have tested pain in different ways, as shown by the authors. The Lange paper has shown that CPIP after Lichtenstein may be related to surgical expertise, one example of a variable that might affect assessed outcomes [3].

The surgeons' ability to identify the IIN intraoperatively also varies significantly, which contributes to the difficulty in assessing CPIP. Previous studies have documented that the Ilioinguinal component may be distributed in the genitofemoral nerve at the level of the first and second lumbar nerves. Several studies have shown that the IIN may be missing in up to $22 \%$ of cases [4].

Brijesh Dube

brijeshdube74@gmail.com

1 Department of Minimal Access, Bariatric, Hernia and GI Surgery, Calcutta Medical Research Institute, 7/2, Diamond Harbour Road, Kolkata, West Bengal 700027, India

2 General and Minimal Access Surgery, Wockhardt Hospitals, Mumbai, India
A previously published prospective multicentric study has shown that the surgeon who can identify all 3 nerves in a Lichtenstein is likely to have the least incidence of CPIP, while the surgeon who does not do so is likely to have a greater incidence [5].

IIN division may not prevent CPIP, as shown in the Lange paper, but it might lead to numbness or paresthesia as a tradeoff. However, as the authors show, the data are not clear on this.

The authors make a valuable point in highlighting the importance of surgeons adopting the DMT (Dermatome Mapping Test) in the assessment of CPIP patients. This may be a common template in which all CPIP data are compared. However, this is possibly more utopian than utilitarian in the present world of surgery.

\section{References}

1. https://www.tga.gov.au/publication/reclassification-surgical-meshdevices

2. Cirocchi R, Sutera M, Fedeli $P$ et al (2021) Ilioinguinal nerve neurectomy is better than preservation in Lichtenstein hernia repair: a systematic literature review and meta-analysis. World $\mathbf{J}$ Surg. https://doi.org/10.1007/s00268-021-05968-x

3. Lange JFM, Meyer VM, Voropai DA et al (2016) The role of surgical expertise with regards to chronic postoperative pain (CPIP) after Lichtenstein correction of inguinal hernia: a systematic review. Hernia 20:349-356. https://doi.org/10.1007/s10029-016-1483-9

4. Wijsmuller AR, Lange JFM, Kleinrensink GJ et al (2007) Nerveidentifying inguinal hernia repair: a surgical anatomical study. World J Surg 30:414-420

5. Alfieri S, Rotondi F, Di Giorgio A et al (2006) Influence of preservation versus division of ilioinguinal, iliohypogastric, and genital nerves during open mesh herniorrhaphy: prospective multicentric study of chronic pain. Ann Surg 243(4):553-558

Publisher's Note Springer Nature remains neutral with regard to jurisdictional claims in published maps and institutional affiliations. 